\title{
Revisión de Randia (Rubiaceae) en Argentina, taxonomía y MORFOANATOMÍA
}

\author{
MARINA D. JUDKEVICH ${ }^{1}$, ROBERTO M. SALAS y ANA M. GONZALEZ
}

\begin{abstract}
Summary: Revision of Randia (Rubiaceae) in Argentina, taxonomy and morpho-anatomy. A revision of the Argentinian species of Randia is presented. According to this study, three species are recognized: $R$. ferox, $R$. micracantha and $R$. calycina, the latter being a new record for the country. It is here proposed exclude Randia armata from the country, a species that is widely and erroneously cited for the area. Taxonomic aspects, vegetative anatomy and pollen morphology of the three species are analyzed. All taxa are described and differentiated through a dichotomous key. Images of diagnostic characters, a distribution map, and ecological observations are included. Lectotypes for the taxon names Basanacantha, $R$. calycina and $R$. ferox are proposed. It is proposed to Randia micracantha var. glabra is treated as a new synonym for Randia micracantha. It was determined that certain anatomic and pollen characters are useful for differentiating the species occurring in Argentina.
\end{abstract}

Key words: Anatomy, Basanacantha, Gardenieae, pollen, taxonomy.

Resumen: Se presenta una revisión de las especies argentinas de Randia. A partir de este estudio se reconocen tres especies: $R$. ferox, $R$. micracantha y $R$. calycina, siendo ésta última una nueva cita para el país. Se propone excluir del país a $R$. armata, especie amplia y erróneamente citada para el área. Se analizaron aspectos taxonómicos, la anatomía vegetativa y morfología polínica de las tres especies. Todos los taxones son descritos y diferenciados a través de una clave dicotómica. Se incluyen además imágenes de los caracteres diagnósticos de las especies, mapa de distribución y observaciones ecológicas. Se proponen lectotipos para los nombres de los taxones Basanacantha, $R$. calycina y $R$. ferox. Randia micracantha var. glabra es tratada como un nuevo sinónimo de Randia micracantha. Se determinó que algunos caracteres anatómicos y polínicos son útiles para la diferenciación de las especies argentinas.

Palabras clave: Anatomía, Basanacantha, Gardenieae, polen, taxonomía.

\section{INTRODUCCIÓN}

Randia L. es un género americano que pertenece a la tribu Gardenieae (Rubiaceae) y consta de 90 especies arbustivas, arbóreas y a veces lianas, que viven en formaciones boscosas desde el nivel del mar hasta los $3300 \mathrm{~m} \mathrm{~s}$. n. m. (Lorence, 1986; Gustafsson, 1998, 2000). Apoyado en aportes morfológicos y principalmente moleculares, Gustafsson (2000) definió al género por tener representantes leñosos y dioicos (con flores funcionalmente imperfectas, pero estructuralmente

Instituto de Botánica del Nordeste (CONICET-UNNE),

Sgto. Cabral 2131, 3400, Corrientes, Argentina.

1 E-mail: marina-judkevich@hotmail.com perfectas), polen en tétradas permanentes, ovario 1-locular con dos placentas parietales, frutos con abundantes semillas inmersas en una pulpa jugosa que al secarse se torna negruzca, y ramas cortas laterales (braquiblastos) comúnmente espinosas en los nudos.

Gustafsson \& Persson (2002) realizaron un estudio filogenético basado en la combinación de caracteres morfológicos y moleculares (5S rsDNA e ITS) en 38 especies del género. Como resultado demostraron que en la concepción actual Randia es un taxón parafilético, cuyas especies aparecen entremezcladas con otros géneros de Gardenieae morfológicamente bien delimitados (Ej. Tocoyena Aubl., Sphinctanthus Benth. y Rosenbergiodendron Fagerl.). En Argentina se reportaron tres especies de Randia (Bacigalupo et al., 2008): R. ferox (Cham. 
\& Schltdl.) DC. en Chaco, Corrientes, Misiones y Formosa, $R$. micracantha (Lillo) Bacigalupo de Jujuy, Salta y Tucumán, y $R$. armata (Sw.) DC. en las provincias de Chaco, Corrientes, Misiones y Formosa. Sobre esta última especie, Delprete et al. (2005) restringieron la aplicación del nombre a plantas de América Central, Antillas y norte de Sudamérica, excluyendo a las plantas del resto de Sudamérica de dicha circunscripción.

En cuanto a la anatomía foliar en Rubiáceas, en términos generales se caracteriza por presentar lámina hipoestomática, mesófilo dorsiventral y haces vasculares colaterales (Metcalfe \& Chalk, 1979; Brouwer \& Clifford, 1990). En general presentan un único tipo de estoma: paracítico (Accorsi, 1947; Carmo de Oliveira et al., 2010; Erbano \& Duarte, 2010; Ribeiro et al., 2011). En Rubiaceae se reconocen varios tipos de domacios: "mechón de pelos", "cavidad" y "bolsillo", y también existen formas intermedias (Barros, 1961). En esta familia es habitual la presencia de coléteres, los cuales tendrían la función de proteger los tejidos meristemáticos de órganos vegetativos y reproductivos a través de la producción de mucílago (Lersten, 1975; Robbrecht, 1988; Thomas, 1991; Thomas \& Dave, 1989a). Thomas (1991) y Robbrecht (1988) mencionan algunos casos en Rubiaceae donde el tipo de coléter, su ubicación, número y estructura tienen importancia taxonómica. Los aportes en aspectos polínicos y anatómicos en especies de Randia del Cono Sur de Sudamérica son realmente escasos (Persson, 1993), incluso a nivel taxonómico.

Por lo expuesto, el objetivo del presente trabajo es caracterizar a las especies de Randia que viven en Argentina, mediante estudios macro y micromorfológicos, aspectos anatómicos, polínicos y ecológicos con el fin de diferenciar taxonómicamente a las especies que habitan el Cono Sur de Sudamérica. Las especies son descritas y sus nombres tipificados, dos de las cuales son también ilustradas por primera vez. Se presentan además mapas de distribución, imágenes de las plantas, detalles de cortes anatómicos de hojas y estípulas, y de granos de polen.

\section{Materiales y Métodos}

Para los estudios taxonómicos se siguieron técnicas convencionales de taxonomía. Se consultaron materiales de los herbarios CTES, CORD, JUA, LIL, MCNS, MO, SI y USZ. En cada material examinado se detalla si pertenece a pie pistilado (P), pie estaminado (E), y si el ejemplar se encuentra en flor (fl) o fruto (fr). Para los estudios morfoanatómicos, se colectaron ápices vegetativos y hojas de individuos de distintas localidades. Los ejemplares testigos se depositaron en el Herbario del Instituto de Botánica del Nordeste, CTES. El material fue fijado en FAA (alcohol $70^{\circ}$, formol, ácido acético, 90:5:5). Para la observación con microscopio óptico (MO) el material se incluyó en parafina según técnica de Johansen (1940) modificada por Gonzalez \& Cristóbal (1997). Se realizaron cortes histológicos seriados longitudinales (CL) y transversales (CT) con micrótomo rotativo a 12-18 $\mu \mathrm{m}$ de espesor, los cuales fueron coloreados con safranina y Astra blue (Luque et al., 1996) y montados con bálsamo de Canadá sintético. Para el análisis de células epidérmicas y estomas, la epidermis foliar se obtuvo mediante la técnica de "maceración controlada", para lo cual porciones de hojas se hirvieron en ácido nítrico al $10 \%$ durante 5 minutos, se aclaró con hipoclorito de $\mathrm{Na}$ al 50\%, se separó la epidermis abaxial del resto de la lámina y se la coloreó con safranina (Pohl, 1967). Se usó la clasificación de Metcalfe \& Chalk (Van Cotthem, 1970) para determinar tipo de estomas. Además se estimó la densidad estomática (número de estomas por $\mathrm{mm}^{2}$ ).

Las observaciones y fotografías se realizaron con microscopio estereoscópico Leica CLS 100X y microscopio óptico Leica DM LV2. Para las observaciones con microscopio electrónico de barrido (MEB), el material fijado se deshidrató en serie acetónica, se secó a punto crítico y fue metalizado con Oro/Paladio según técnicas usuales. Se utilizó MEB Jeol LV 5800. Las muestras para estudios polínicos se tomaron del herbario CTES, las cuales fueron acetolizadas según Erdtman (1966), analizadas mediante MEB y MO. La terminología utilizada sigue a Punt et al. (2007).

\section{Resultados}

Tratamiento taxonómico

Randia L., Sp. Pl. 2: 1192. 1753. Lectotipo: Randia mitis L. (designado por Hitchcock \& Green, 1929, = Randia aculeata L.). 
Basanacantha Hook. f. en Benth. \& Hook. f., Gen. Pl. 2: 82. 1873. Lectotipo: Basanacantha hebecarpa (Benth.) Hook. f., Gen. P1. 2: 82. 1873. (aquí designado). (= Randia hebecarpa Benth.).

Árboles, arbustos y a veces lianas, dioicos, generalmente con espinas caulinares. Hojas opuestas, raramente verticiladas, sésiles o pecioladas; lámina elíptica, oblonga, ovada, obovada o espatulada, membranácea o coriácea; con o sin domacios en las axilas de las venas secundarias y terciarias. Estípulas interpeciolares triangulares, con coléteres en su cara interna. Inflorescencias cimosas, uni a multifloras. Inflorescencia terminal o axilar, cimosa, o flores solitarias. Flores funcionalmente imperfectas, actinomorfas, (4-)5(-7)-meras; cáliz dentado o lobulado, a veces con lóbulos foliáceos, externamente glabro o pubescente, persistente; corola actinomorfa, hipocraterimorfa o infundibuliforme, garganta pilosa o glabra, lóbulos con prefloración contorta; estambres fijos en la parte superior del tubo corolino, anteras dorsifijas, estaminodios en flores pistiladas; polen en tétradas; ovario 2-4 locular con numerosos óvulos inmersos en una placenta carnosa, prominentes; estilo de ápice 2-lobado, pistilodio en flores estaminadas. Fruto bayáceo, coronado por el cáliz, indehiscente, con semillas numerosas, inmersas en el tejido placentario, gelatinoso, dulce; semillas orbiculares, albuminadas.

Distribución y hábitat: se distribuye en América, desde el sur de Estados Unidos hasta el norte de la Argentina, Paraguay y sur de Brasil (Delprete, 2010; Delprete et al., 2005). Habita en formaciones boscosas siempreverdes o deciduas, desde el nivel del mar hasta los $3300 \mathrm{~m} \mathrm{s.} \mathrm{n.} \mathrm{m.}$

Observación: de acuerdo a lo estudiado, el nombre del sinónimo Basanacantha Hook. f. carece de especie tipo. El autor citó en el protólogo a cinco nombres específicos morfológicamente afines: Basanacantha dioica (H. Karst.) Hook. f., B. hebecarpa, B. humboldtiana (Roem. \& Schult.) Benth. \& Hook. f. ex B. D. Jacks., B. monantha (Benth.) Hook. f. y B. tetracantha (Cav.) Hook. f. De esos nombres, se designa como especie tipo a Basanacantha hebecarpa, de acuerdo al artículo 10 del ICN (McNeill et al., 2012), porque reúne todas las características morfológicas que se mencionan en el protólogo del género.

\section{Clave para diferenciar las especies de Randia en Argentina}

1a. Ramas con un verticilo subapical de espinas seguido por 1 o más braquiblastos (Fig. $1 \mathrm{~A}$ ), espinas angostamente cónicas, no quebradizas; corola hipocrateriforme blanca, tubo 10,7-27 $\mathrm{mm}$ (P), 14-34 mm long. (E); polen psilado.

2a. Hoja con lámina pubescente o híspida; sin domacios; flores pistiladas con lóbulos del cáliz obovados o espatulados, pubescentes; tubo de la corola 10,7-16,1 mm (P), 14-16,1 $\mathrm{mm}$ (E) long.; fruto maduro pubérulo, 1,3$3,5 \mathrm{~cm}$ long., con lenticelas; pared delgada, consistencia coriácea, 0,3-0,6 mm de espesor.

\section{Randia calycina}

2b. Hoja con lámina glabra o pubérula, con domacios tipo mechón de pelos; flores estaminadas y pistiladas con lóbulos del cáliz angostamente triangulares, glabros; tubo de la corola 25-27 mm (P), 22,6-34 mm (E) long.; fruto maduro glabro, $3-5 \mathrm{~cm}$ long., sin lenticelas, pared gruesa, consistencia leñosa, 1,2-3,5 $\mathrm{mm}$ de espesor.

\section{Randia ferox}

1b. Ramas con más de dos verticilos de espinas, cada uno seguido de un macroblasto o de un braquiblasto (Fig. 1 B), espinas aciculares y quebradizas; corola infundibuliforme verdeamarillenta, tubo ca. 3,1 mm (P), 1,5-3 mm long. (E); polen reticulado.

\section{Randia micracantha}

1. Randia calycina Cham., Linnaea 9: 246. 1834. Basanacantha calycina (Cham.) K. Schum., Fl. Bras. 6 (6): 375. 1888. Tipo: Brasil. Bahia, prope Nazaré, F. Sellow 163 (lectotipo, aquí designado, K 000265550!; isolectotipos S08-13880!, S0813881!, S08-13882!, S08-13883!). Figs. 2, 4 A-D.

Arbustos 2-5 m alt., ramas escasa o densamente pubescentes, espinas 2-4 por nudo, leñosas, 5-15,2 mm long., nudo de espinas rematando apicalmente en 1 o 2 braquiblastos. Estípulas deciduas, lóbulos 2-4 mm de long., ovadas, agudas a acuminadas, margen piloso, externamente glabras o esparsamente vilosas, con coléteres y tricomas en la base de la cara interna. Hojas sésiles o pecioladas, pecíolos (cuando presentes) de 4-14 $\mathrm{mm}$ de 


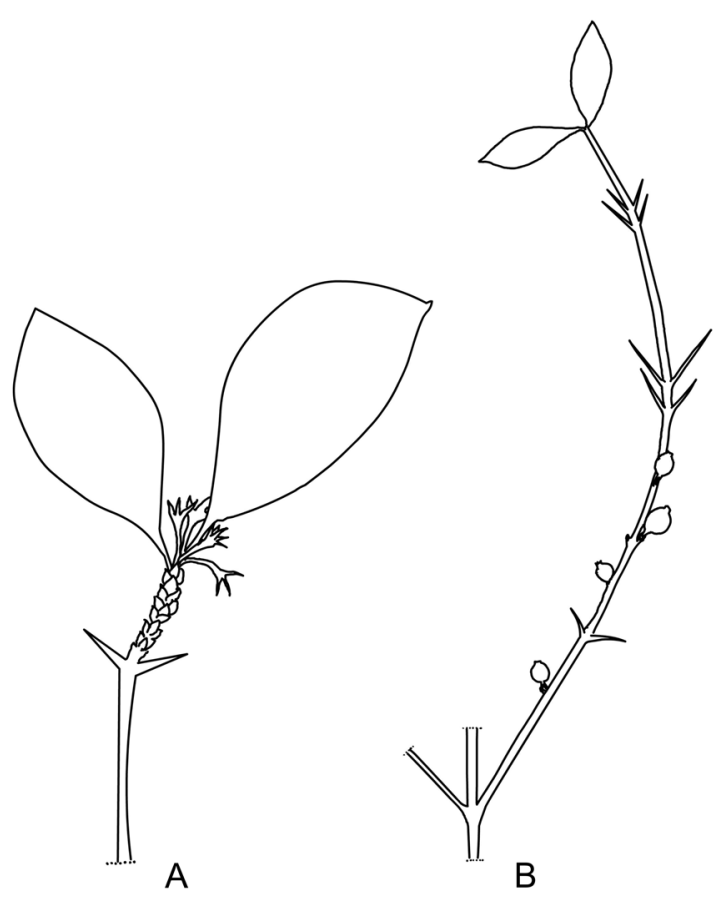

Fig. 1. Esquema de los dos tipos encontrados de ramas. A. Rama con un verticilo subapical de espinas ( $R$. calycina, $R$. ferox). B. Rama con más de dos verticilos de espinas ( $R$. micracantha).

long., pubescentes; láminas elípticas, anchamente elípticas o anchamente obovadas, 2-12 × 1,2-7 cm, ápice agudo o acuminado, a veces mucronadas, agudas en la base, papiráceas, adaxialmente glabras, pubescentes o tomentosas, adaxialmente híspidas o vilosas; con 5-9 venas secundarias a ambos lados de la principal, ascendentes, con indumento más acentuado que en el resto de la lámina; sin domacios. Inflorescencia estaminada fasciculada, 3-12-flora, sésil. Flor estaminada (4-)5(-6)-mera, cáliz lobulado, hipanto obcónico, pubescente, 3,5-6,9 $\mathrm{mm}$ de long.; lóbulos lineares, oblongos o angostamente ovados, esparsamente pubescentes o vilosos en ambas caras, 1,8-7 mm de long.; corola (4-)5(-6)-mera, hipocrateriforme; tubo verdoso, 14-20,7 × 1,5-2,2 mm, pubérulo o pubescente, internamente pubescente en la porción media superior hasta la base de los lóbulos, lóbulos ovados u obovados, ápice redondeado, blancos, 3,3-6 mm de long.; estambres inclusos o parcialmente exertos, anteras sésiles; pistilodio incluso o parcialmente exerto; región estigmática lisa, bilobada. Inflorescencia pistilada 1-flora, sésil. Flor pistilada (4-)5(-6)-mera, cáliz lobado, hipanto angostamente elipsoide, pubescente, pelos antrorsos, 5-7 mm de long.; lóbulos obovados a espatulados, obtusos o agudos, pubescentes en ambas caras, 4,9-18 mm de long.; corola (4-)5(-6)mera, hipocrateriforme; tubo cilíndrico, verdoso, externamente pubérulo, pubescente desde la mitad superior hasta la base de los lóbulos, 10,7-16,3 × 1,8-2,6 mm; lóbulos redondeados o anchamente ovados, blancos, 2,2-4,5 mm de long.; estambres inclusos o parcialmente exertos; anteras estériles, sésiles; estilo incluso o parcialmente exerto, glabro; estigma papiloso, bífido, ramas estigmáticas ovadas. Fruto ovoide a elipsoide, liso o débilmente costado, glabro o escasamente pubérulo, pubescente cuando inmaduro, verde-grisáceo y con lenticelas al madurar, 13-35 ×12,7-19 $\mathrm{mm}$; coronado por el disco y por restos de cáliz; pared del fruto de consistencia coriácea cuando se seca, 0,3-0,6 mm de espesor; semillas suborbiculares a obovadas, 5-5,7 $\times 6,7-8,3 \mathrm{~mm}$, comprimidas, pardas, inmersas en el tejido placentario.

Distribución y hábitat: Sudamérica. En el Cono Sur habita en el S de Brasil, Paraguay y NE de Argentina (Fig. 5). Habita en el interior de bosques de galería o en bosques de Schinopsis balansae Griseb., típico de la región oriental de la provincia fitogeográfica Chaqueña (Morrone, 2014).

Fenología: flores de septiembre a noviembre, frutos desde noviembre a abril.

Observación: debido a que el holotipo depositado en $\mathrm{B}$ fue destruido, se elige el isotipo en $\mathrm{K}$ (K000265550) como lectotipo.

Material adicional examinado: ARGENTINA. Prov. Chaco: Dpto. Bermejo, Isla del Cerrito, 10X-1971 (E, fl), Krapovickas \& Cristóbal 20055 (CTES); ídem, Colonia Benítez, 28-XI-2014 (P, fl, fr), Judkevich \& Salas 57 (CTES); Dpto. San Fernando, Barranqueras, Paranacito, 7-IV-2007 (P, fr), Rotta 453 (CTES); ídem, 2-II-2007 (P, fr), Rotta 426 (CTES). Prov. Formosa: Dpto. Formosa, $12 \mathrm{~km}$ sur de Formosa, 19-VI-1975 (P, fr), Krapovickas \& Schinini 28515 (CTES). Dpto. Laishi, Reserva Ecológica El Bagual, San Francisco de Laishi, 8-IX-1996 (E, fl), Digiacomo 268b (CTES). Dpto. 


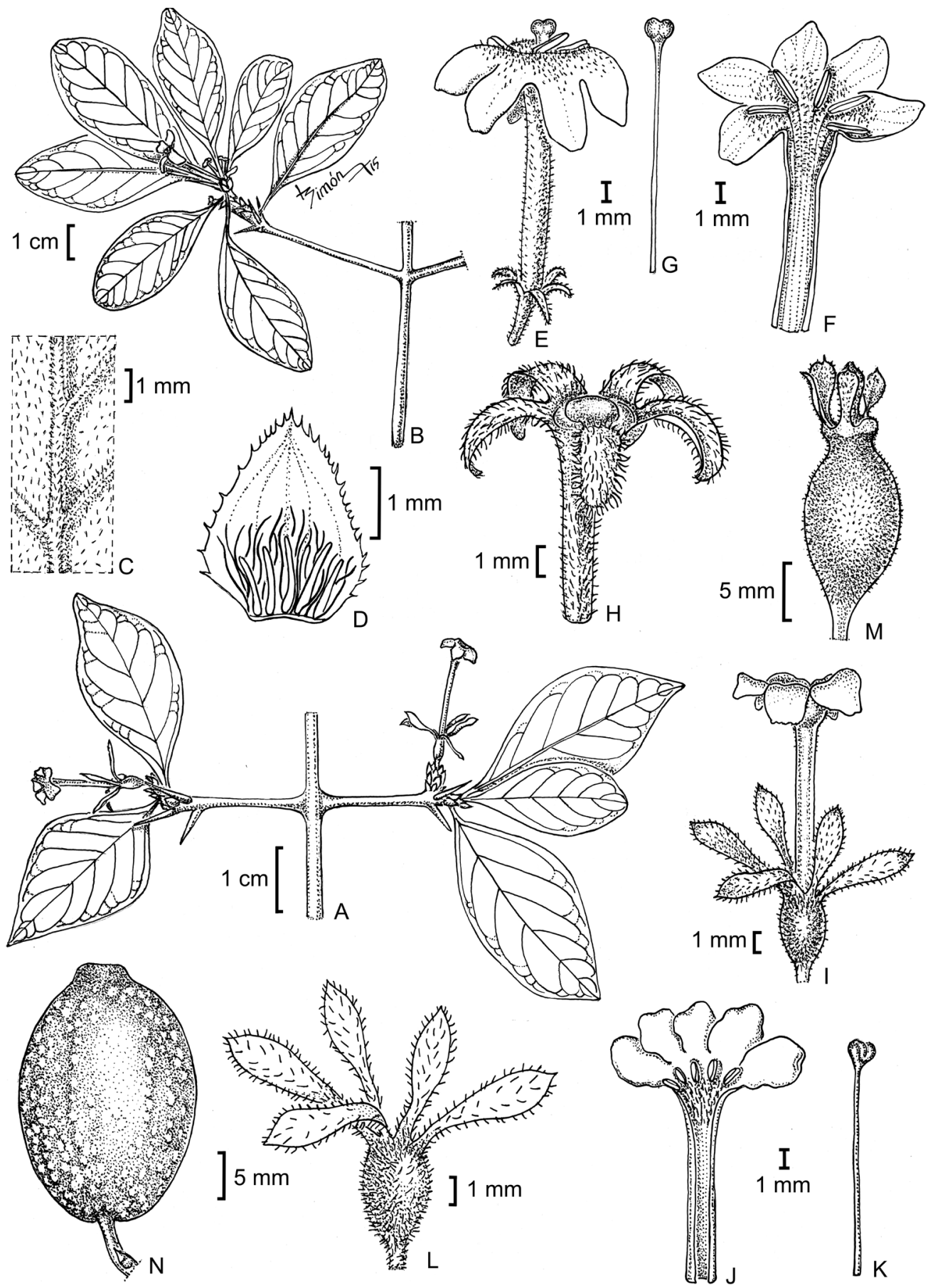

Fig. 2. Randia calycina. A. Rama de pie pistilado. B. Rama de pie estaminado. C. Detalle de la cara abaxial de la hoja. D. Detalle de la cara interna de la estípula con coléteres. E-H. Flor estaminada. E. Flor completa. F. Corola desplegada. G. Pistilodio y región estigmática. H. Detalle del cáliz y disco nectarífero. I-L. Flor pistilada. I. Flor completa. J. Corola desplegada. K. Estilo y estigma. L. Detalle del hipanto. M. Fruto inmaduro. N. Fruto maduro. Ilustraciones: Laura Simón. B, E-H: Placci \& Arditi 133 (CTES). A, C-D, I-L: Vera et al., 98 (CTES). M: Placci \& Arditi 170 (CTES). N: Judkevich \& Salas 57 (CTES). 
Pilcomayo, Estancia Guaycolec, $25 \mathrm{~km}$ norte de Formosa, Ruta Nacional 11, 20-X-1989 (E, fl), Placci \& Ardite 133 (CTES); ídem, 1-XI-1989 (P, fl), Placci \& Arditi 170 (CTES); ídem, 10-IX2014 (P, fl), Judkevich \& Salas 49 (CTES); idem, 10-IX-2014 (E, fl), Judkevich \& Salas 52 (CTES); idem, Monte Lindo, 11-IX-2014 (E, fl), Judkevich \& Salas 54 (CTES); ídem, Ruta 11, ca. $50 \mathrm{~km} \mathrm{~N}$ de Formosa, alrededores del arroyo Monte Lindo, $25.7870^{\circ} \mathrm{S}, 58.0176^{\circ} \mathrm{W}, 1-\mathrm{II}-2007$ (P, fr), PaulaSouza et al. 8145 (CTES); ídem, Río Pilcomayo (Meicoocue), 12-XI-1986 (P, fr), Vergara 2 (CTES). PARAGUAY. Dpto. Presidente Hayes, Estancia Maroa, 2332'33"S, 57 54'7' W, 19-X-2004 (P, fl), Vera et al. 98 (CTES); Villa Hayes, Estancia La

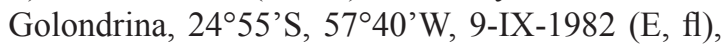
Hahn 683 (CORD, MO).

2. Randia ferox (Cham. \& Schltdl.) DC., Prodr. 4: 387. 1830. Gardenia ferox Cham. \& Schltdl., Linnaea 4: 198. 1829. Tipo: Brasil. Rio Padre, 18141831, F. Sellow s.n (Lectotipo, aquí designado, HAL 144110!). Figs. 3, 4 E-I.

Árbol o arbusto de 3-15 m alt., ramas glabras; espinas 2-4 por nudo, leñosas, 5,1-19,7 mm long., nudo de espinas rematando apicalmente en 1 o 2 braquiblastos. Estípulas deciduas, lóbulos 3-8 $\mathrm{mm}$ de long., anchamente ovadas, mucronadas o acuminadas, margen liso, glabras externamente, con coléteres y tricomas en la base de la cara interna. Hojas pecioladas, pecíolos $5-20 \mathrm{~cm}$ de long., glabros; láminas ovadas, oblongo-ovadas u obovadas, 2,25-12,7 × 1,2-6,9 cm, ápice agudo u obtuso, base aguda o acuminada, papiráceas, glabras o esparsamente pubérulas; con 4-7 venas secundarias a cada lado, ascendentes, pubérulas o pubescentes, con domacios tipo mechón de pelos ubicados en la intersección de la vena principal y las secundarias. Inflorescencia estaminada fasciculada, 3-8(-10)-flora. Flor estaminada 4-5-mera; cáliz lobulado, hipanto obcónico, glabro, 5,8-13,1 mm de long., lóbulos obovados, glabros, 3,7-9 mm de long.; corola hipocrateriforme, tubo cilíndrico, verdoso, externamente glabro, pubescente desde la porción media superior hasta la base de los lóbulos, 22,6-34 × 2,5-4 mm; lóbulos de la corola ovados u obovados, ápice redondeado, blancos con la base ligeramente amarillenta, 5,7-11,4 $\mathrm{mm}$ de long.; estambres inclusos o parcialmente exertos; anteras sésiles insertas en la garganta de la corola; pistilodio incluso o parcialmente exerto, región estigmática lisa 2-lobada, disco nectarífero entero. Inflorescencia pistilada 1-flora. Flor pistilada 4-5-mera, cáliz lobulado, hipanto urceolado, glabro, 14,2-19,1 mm de long., lóbulos angostamente triangulares, glabros, $4-5 \mathrm{~mm}$ de long.; corola hipocrateriforme, glabra externamente, tubo cilíndrico, verdoso, glabro externamente, pubescente desde la mitad superior hasta la base de los lóbulos; lóbulos redondeados o anchamente ovados, blancos con la base amarillenta, 5,7-8,6 $\mathrm{mm}$ de long.; estambres inclusos o parcialmente exertos; anteras estériles, sésiles, insertas en la garganta de la corola; estilo parcialmente exerto, con 2 ramas estigmáticas ovadas, papilosas. Fruto ovoide, obovoide, elipsoide, globoso o subgloboso, liso o ligeramente costado, glabro o con escasos pelos dispersos, amarillo o anaranjado cuando maduro, $30-50 \times 25-30 \mathrm{~mm}$, coronado por el disco y por restos de cáliz, pared del fruto de consistencia leñosa cuando se seca; pared 1,2-3,5 $\mathrm{mm}$ de espesor; semillas suborbiculares, 7-9 × 5-6 $\mathrm{mm}$, comprimidas, pardas, inmersas en el tejido placentario.

Distribución y hábitat: Sudamérica. En el Cono Sur habita en el NE de Argentina, sur de Brasil y Paraguay oriental. En Argentina vive en Corrientes y Misiones (Fig. 5). Habita en bosques mesófilos sobre lomadas arenosas, en el interior o al borde de bosques higrófilos.

Fenología: Flores desde septiembre a abril, con picos de floración en septiembre y octubre, frutos todo el año, especialmente desde febrero a agosto.

Observación: el holotipo depositado en B fue destruido, por lo tanto se elige el material de HAL como lectotipo debido a que es el único que pudo ser asociado con seguridad al protólogo de la especie.

Material adicional examinado: ARGENTINA. Prov. Corrientes: Dpto. Concepción, 7-X-1972 (E, fl), Pedersen 10206 (CTES); Dpto. Capital, $5 \mathrm{~km}$ E de Laguna Brava, 6-IX-1970 (E, fl), Krapovickas \& Cristóbal 15849 (CTES); Dpto. Itatí, $10 \mathrm{~km} \mathrm{E}$ de Itatí, $1 \mathrm{~km} \mathrm{~N}$ de camino vecinal, 20-X-1982 (P, fr), Carnevali 5892 (CTES); Dpto. 


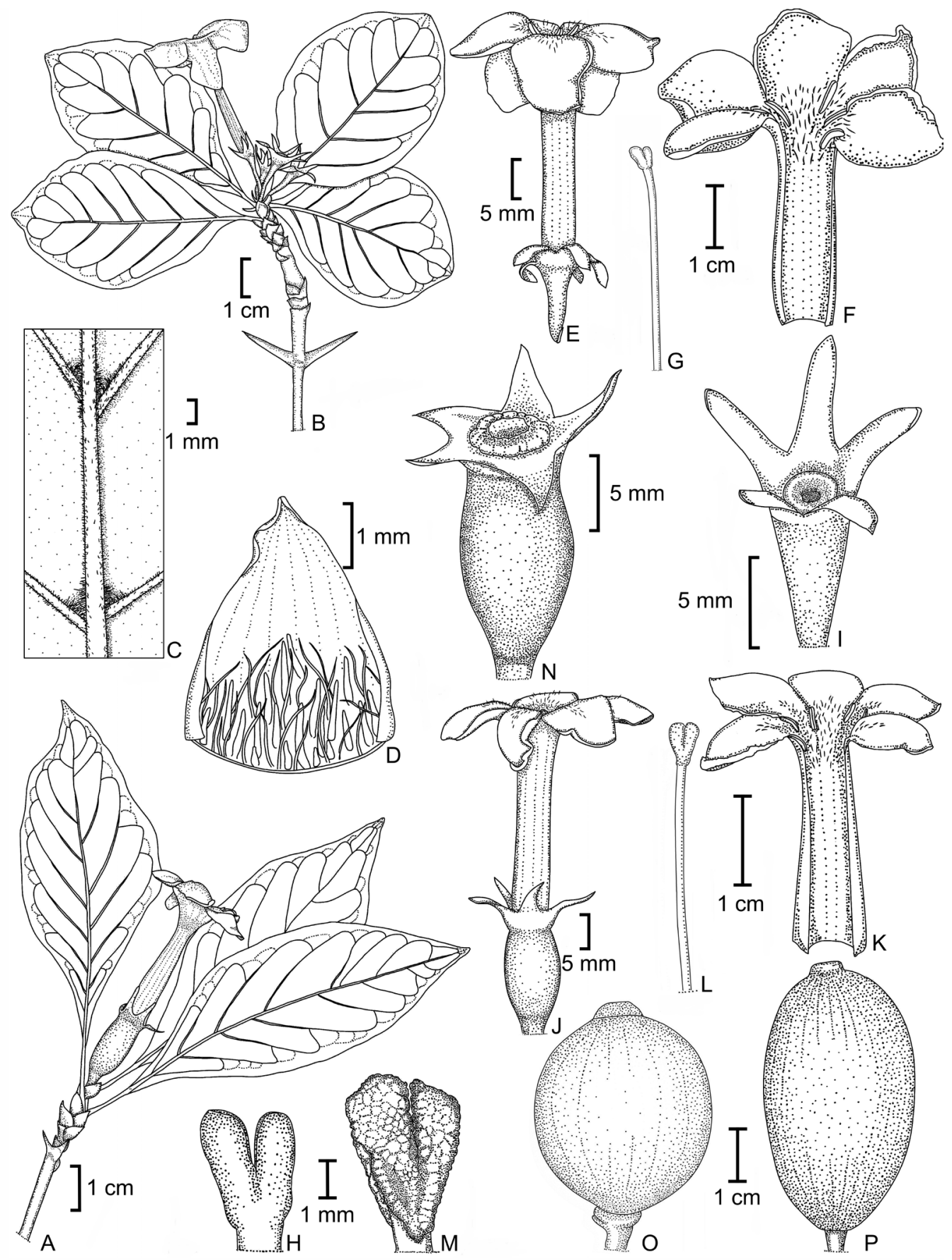

Fig. 3. Randia ferox. A. Rama de pie pistilado. B. Rama de pie estaminado. C. Detalle de la cara abaxial de la hoja con domacios. D. Detalle de la cara interna de la estípula con coléteres. E-I. Flor estaminada. E. Flor completa. F. Corola desplegada. G. Pistilodio y región estigmática. H. Detalle de la región estigmática. I. Detalle del cáliz y disco nectarífero. J-N. Flor pistilada. J. Flor completa. K. Corola desplegada. L. Estilo y estigma. M. Detalle del estigma. N. Detalle del hipanto y disco nectarífero. O. Fruto maduro globoso. P. Fruto maduro elipsoide. B-I: Keller et al., 4436 (CTES). A, J-N: Schinini et al., 28784 (CTES). O-P: Medina \& Salas 384 (CTES). 

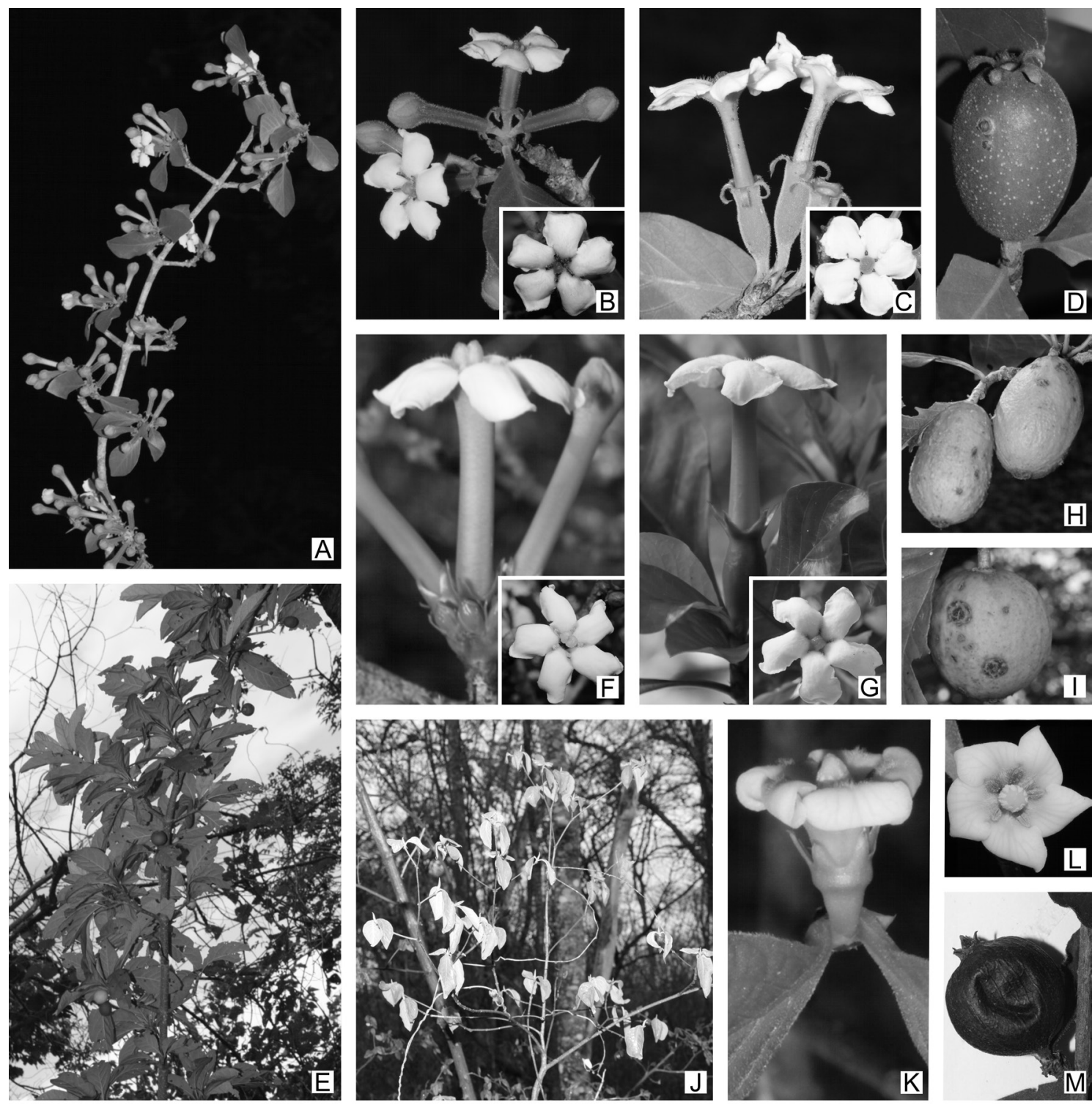

Fig. 4. A-D: Randia calycina. A: Rama con flores estaminadas. B: Flores estaminadas y detalle de la corola (abajo). C: Flores pistiladas y detalle de la corola (abajo). D: Fruto maduro con lenticelas. E-I: R. ferox. E: Rama con frutos. F: Flores estaminadas y detalle de la corola (abajo). G: Flor pistilada y detalle de la corola (abajo). H: Fruto maduro ovalado. I: Fruto maduro globoso. J-M: R. micracantha. J. Rama. K: Flor estaminada. L: Detalle de la corola. M: Fruto maduro (material de herbario).

Ituzaingó, Río Aguapey y Ruta 38, 4-XII-1980 (P, fr), Tressens 1182 (CTES); idem, establecimiento Santo Domingo, mogote C, 27 $41^{\prime} 27.8^{\prime \prime} \mathrm{S}$, 56 ${ }^{\circ} 10$ '31.2” W, 7-II-2013 (P, fr), Keller et al. 11256 (CTES); ídem, 17 km NW de San Carlos, Estancia Rincón Chico, 14-II-1991 (P, fr), Tressens et al. 3909 (CTES); idem, Puerto Valle, 27³5'10.1'S,
56³0'50.4"W, 3-X-2013 (E, fl), Keller 11667 (CTES); Dpto. San Cosme, Río Paraná y Arroyo San Juan 25-V-1975 (P, fr), Schinini \& Quarín 11523 (CTES); Dpto. San Martín, Cerro Capará, 9-IV-2013 (E, fl), Medina \& Salas 384 (CTES). Prov. Misiones: Dpto. Candelaria, San Juan, 13-VII-1974 (P, fr), Schwindt 374 (CTES, LIL); 


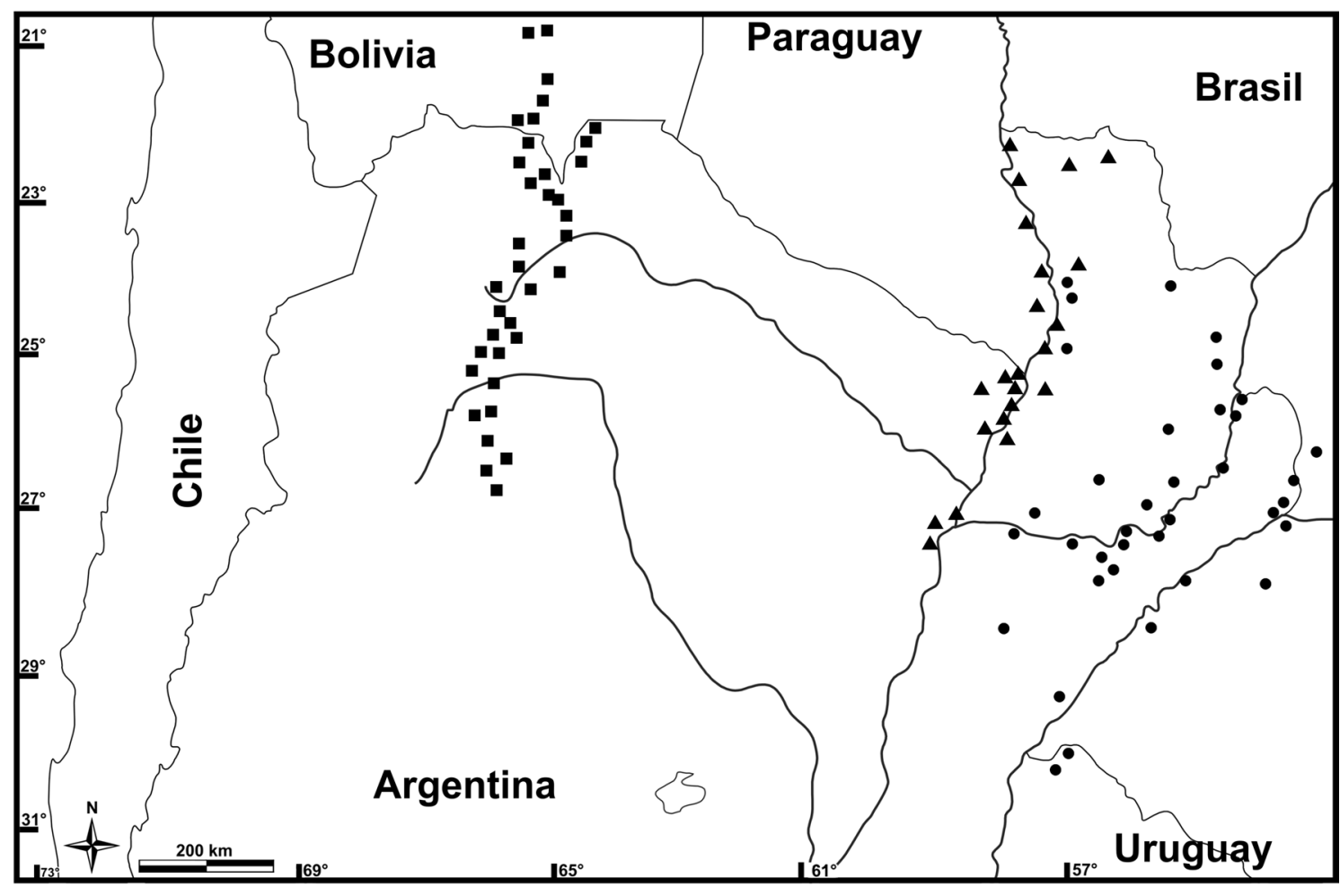

Fig. 5. Mapa de distribución de Randia calycina $(\mathbf{\Delta}), R$. ferox $(\bigcirc)$ y $R$. micracantha ( $\boldsymbol{\square}$ ) en el Cono Sur de Sudamérica.

Dpto. Guaraní, picada al Arroyo Soberbio, predio Guaraní, 26054'59"S, 54¹2'18”W, 9-IX-1994 (P, fl, fr), Schinini et al. 28784 (CTES); Dpto. Capital, Posadas, 22-IV-1945 (P, fr), Bertoni 1317 (CTESLIL); Dpto. San Javier, Villa Bonita, 2-X-1948 (E, fl), Bertoni 3782 (CTES, LIL); Dpto. San Pedro, Colonia San Lorenzo, 29-IX-2007 (E, fl), Keller et al. 4436 (CTES); idem, Parque Provincial Moconá, Mirador del Yaboty, 2709'03.67"S 53'54'51.09" W, 7-III-2013 (E, fl), Judkevich et al. 34 (CTES). BRASIL. Estado Paraná: Municipio Araucaria, Novo Nordisk, 14-XII-1998 (P, fr), Gatti \& Gatti 336 (CTES). Estado Rio Grande do Sul: Santa Maria, Reserva Biológica do Ibicuí-Mirim, 4-X1989 (P, fr), Bonotto 22 (CTES). PARAGUAY. Dpto. Itapúa: Pirapó, CEDEFO, 26³0’S, 56 50’ W, 4-VIII-1984 (P, fr), Hahn \& de Molas 2761 (CORD, $\mathrm{MO})$.

3. Randia micracantha (Lillo) Bacigalupo, Fl. Prov. Jujuy 9: 388. 1993. Basanacantha micracantha Lillo, Prim. Reun. Nac. Soc. Argentina Ci. Nat.:
218. 1916. Tipo: Argentina. Tucumán, Monteros, bosque Pueblo Viejo, IX-1905 (PE, fl), Lillo 4536 (Lectotipo, LIL 001565!, designado por Bacigalupo, 1993: 388). Fig. 4 J-M.

Randia micracantha (Lillo) Bacigalupo var. glabra Bacigalupo, Fl. Prov. Jujuy 9: 391. 1993. nov. syn. Tipo: Argentina. Jujuy, Capital, Alto Lozano a Tiraxi, 3-XI-1974, Correa et al. 6084 (Holotipo SI!).

Subarbusto, arbusto o pequeño árbol de 0,3$4 \mathrm{~m}$ de alt., caducifolio, dioico; ramas escasa a densamente pubescentes, con más de dos verticilos de espinas por rama, espinas 2-4 por nudo, cada nudo seguido de un macroblasto o de un braquiblasto seguido a su vez por un macroblasto, espinas delgadas y quebradizas, leñosas, glabras, oblicuo-ascendentes, $0,4-2,5 \times 0,8-1,3 \mathrm{~mm}$. Estípulas deciduas, lóbulos triangulares, 1,6-7 $\mathrm{mm}$ de long., externamente glabras, internamente pubescentes y con coléteres en la base. Hojas 
sésiles o cortamente pecioladas, pecíolos 1,4-6 mm de long.; láminas elípticas u obovadas, rara vez ovadas, 1,3-12,2 × 1,8-5,2 cm, ápice agudo u obtuso, a veces mucronadas, base cuneiforme o atenuada, densamente pubescentes en ambas caras, pubérulas o glabras; con 5-9 venas secundarias a cada lado, pubescentes, ascendentes; sin domacios. Inflorescencia estaminada cimosa, 1(-2)-flora, en 4-8 braquiblastos axilares o terminales, densamente ubicados, cada uno finalizando en inflorescencias 1-flora, raramente braquiblastos floríferos solitarios. Flor estaminada 4-5-mera; cáliz lobulado, hipanto obcónico, pubescente o hirto, 2-4 mm de long., lóbulos angostamente triangulares o subovados, obtusos o apiculados, ápice ciliado o glabro, 1,4-3,2 $\mathrm{mm}$ de long.; corola lobada, infundibuliforme, tubo verdoso, glabro externamente, internamente con pelos en la garganta, 1,5-3 × 2-3 mm; lóbulos de borde irregularmente revoluto, amarillos-verdosos, 2-4 mm de long.; anteras sésiles, conectivo apiculado; pistilodio parcialmente exerto, región estigmática lisa, 2-lobada, disco nectarífero entero. Inflorescencia pistilada 1-flora. Flor pistilada 5(-4)mera, cáliz lobado, hipanto elipsoide, pubescente, 2-4 mm de long., lóbulos angostamente triangulares o subovados, obtusos o apiculados, ápice recurvo, glabros, borde ciliado, amarillo-verdosos, 1,4$3 \mathrm{~mm}$ de long.; corola infundibuliforme, tubo verdoso, garganta pubérula o pubescente, ca. 3,1 $\mathrm{mm}$ de long.; lóbulos amarillo-verdosos, borde revoluto, 2-4 $\mathrm{mm}$ de long.; anteras indehiscentes, estériles, con tecas apiculadas; estilo con estigma papiloso 2-lobado, ramas estigmáticas ovoides, disco nectarífero entero. Fruto globoso o elipsoide, pubérulo, verde-grisáceo, 12,2-21 × 9,6-13,8 mm, coronado por el disco y por restos de cáliz, pared del fruto de consistencia coriácea cuando se seca; pared de 0,18-0,29 $\mathrm{mm}$ de espesor; semillas suborbiculares, $5-6,3 \mathrm{~mm} \times 3,5-4 \mathrm{~mm}$, comprimidas, inmersas en el tejido placentario.

Distribución y hábitat: exclusiva de bosques estacionalmente secos y semideciduos de las Yungas (pedemonte, selvas y bosques montanos de las Yungas Tucumano-Bolivianas), entre los 600 y 2300 m s. n. m. En Argentina habita en las provincias de Jujuy, Salta y Tucumán (Fig. 5).

Fenología: flores desde septiembre a diciembre, frutos de diciembre a mayo.
Iconografia: Bacigalupo, 1993, fig. 158.

Observación: en el campo se observó que esta especie presenta dos tipos de hojas, las hojas que acompañan a la floración (PF, periodo de floración) de tamaño pequeño presentes al final de la temporada seca, y las hojas del periodo vegetativo (PV), que son 3-4 veces más grandes que las primeras y se encuentran junto a frutos o en estado vegetativo, durante la temporada de lluvias (octubre-mayo). El análisis de los caracteres morfológicos de las subespecies $R$. micracantha y $R$. glabra mostró que las diferencias utilizadas por Bacigalupo (1993) para separar ambas no son discretas. Se encontraron variaciones graduales desde glabras hasta pubescentes. Por esto, Randia micracantha var. glabra es aquí tratada como un nuevo sinónimo de la variedad típica.

Material seleccionado: ARGENTINA. Prov. Jujuy: Dpto. El Carmen, dique Las Maderas, sur de Perico, II-1997 (P, fr), Protomastro 1230 (CTES, MCNS). Dpto. San Pedro, Ruta Provincial 56, $13-$ V-1998 (P, fr), Krapovickas et al. 47412 (CTES). Dpto. Santa Bárbara, Sierras de Maíz Gordo, límite con la provincia de Salta, $24^{\circ} 17^{\prime} \mathrm{S}, 65^{\circ} 11^{\prime} \mathrm{W}$, 15-XII-1998 (E, fl), Ahumada et al. 9025 (CTES, JUA); ídem, El Fuerte, 9-XII-1983 (E, fl), Roitman 779 (CTES, JUA); Prov. Salta: Dpto. Capital, Villa San Lorenzo, Quebrada de Arteaga, finca "Las Costas", 2944.87'S, 65³0.958'W, 15-I-2014 (P, fr), Judkevich 48 (CTES); idem, La Lagunilla, 26V-1989 (P, fr), Toledo 2127 (CTES); Dpto. Metán, sin localidad, 8-XII-1946 (P, fr), Álvarez 126 (CTES, LIL); Dpto. Orán, Orán a Río Bermejo, X-1940 (E, fl), Schreiter 115454 (CTES-LIL); ídem, Palo de Santo Domingo, tabacal cerca de Orán, 17-VII-1873 (P, fr), Lorentz \& Hieronymus s.n. (CORD); Dpto. San Martín, Aguaray, 21-IX-2012 (E, fl), Salas 491 (CTES); Dpto. Santa Victoria, Los Toldos, $7 \mathrm{Km}$ antes de llegar a Lipeo, 15-IX1972 (E, fl), Mármol et al. 9300 (CTES, LIL). Prov. Tucumán: Dpto. Capital, VII-1901 (E, fl), Lillo 2834 (CORD, LIL); ídem, ruta hacia Cristo de San Javier, 14-IX-2005 (P, fr), Keller 3149 (CTES); Chicligasta, puerto Santa Rosa, 28-II-1950 (P, fr), Meyer 15502 (CTES); Monteros, S de El Mollar, 9-XI-1974 (E, fl), Subils 2058 (CORD). BOLIVIA. Dpto. Chuquisaca: Prov. Luis Calvo, El SalvadorCIMBOC, $3 \mathrm{~km} \mathrm{~S}$ de Isirenda, 204'스. $63^{\circ} 11^{\prime} \mathrm{W}$, 
10-IV-1993 (P, fr), Toledo et al. 11596 (CTES). Dpto. Cochabamba: camino de Mizque a Aiquile, sendero cercano al cerro Ork'o, Abuelo, 30-X-1992 (E, fl), Antezana 423 (CTES). Dpto. Santa Cruz: Prov. Vallegrande, camino a Vallegrande, $3 \mathrm{~km} \mathrm{NW}$ de Cochabambita, $18^{\circ} 13^{\prime}$ 'S, $64^{\circ} 12^{\prime}$ 'W, 28-XII-1988 (P, fr), Saldias 538 (CTES, USZ). Dpto Tarija: Prov. Arce, comunidad Guavillas, $23.8 \mathrm{~km} \mathrm{~S}$ of Padcaya on road to Bermejo, 21 ${ }^{\circ} 59^{\prime} \mathrm{S}, 64^{\circ} 40^{\prime} \mathrm{W}, 27-\mathrm{IV}-1983$ (P, fr), Solomon 10187 (CTES, MO); Cuesta del Tambo, entre el Tambo y Narvaes, 11-VI-1873 (P, fr), Lorentz \& Hieronymus 889 (CORD).

\section{Estudios polínicos}

Las tres especies presentaron tétradas tetraédricas y decusadas, siendo las primeras las más abundantes. Los granos de polen aislados son simétricos y cada uno presenta tres poros circulares. Randia calycina: tétradas tetraédricas, 43-(50,27)-

$63 \mu \mathrm{m}$; granos 27,3-(28,58)-29,8 $\mu \mathrm{m}(\mathrm{P})$ y $32,7-$ (33,2)-33,7 $\mu \mathrm{m}$ (E); poros 3,7-(4,82)-5,9 $\mu \mathrm{m}$, exina psilada, 1,36-1,6 $\mu \mathrm{m}$ de espesor. Tétradas decusadas 55,1-(55,77)-56,45 $\mu \mathrm{m}$; granos 27,6$(28,22)-28,8 \mu \mathrm{m}(\mathrm{P})$ у $33-(33,59)-34,2 \mu \mathrm{m}(\mathrm{E})$, poros 3-(3,23)-3,45 $\mu \mathrm{m}$; exina psilada, 1,19-1,5 $\mu \mathrm{m}$ de espesor (Fig. 6 A-C).

Randia ferox: tétradas tetraédricas, 56,2-(61,38)$66,9 \mu \mathrm{m}$; granos 28,5-(32,09)-39,9 $\mu \mathrm{m}(\mathrm{P})$ y 41,3-(45,25)-48,8 $\mu \mathrm{m}$ (E); poros 6,36-(7,12)7,8 $\mu \mathrm{m}$; exina psilada, 1,5-(1,7)-1,8. Tétradas decusadas 53,45-(58,76)-66 $\mu \mathrm{m}$, granos 30,4(32,96)-36 $\mu \mathrm{m}(\mathrm{P})$ у 42,6-(45,69)-48,3 $\mu \mathrm{m}(\mathrm{E})$; poros 5,9-(7,11)-8,5 $\mu \mathrm{m}$; exina psilada, 1,6-(2)2,2 $\mu \mathrm{m}$ de espesor (Fig. 6 D-F).

Randia micracantha: tétradas tetraédricas, 42,9(48,17)-56,2 $\mu \mathrm{m}$; granos 26,9-(27,64)-28,8 $\mu \mathrm{m}$ (P) y $34,4-(37,25)-39,8 \mu \mathrm{m}(\mathrm{E})$; poros $4,9-$ (5,54)-6,5 $\mu \mathrm{m}$; exina reticulada, 1,9-(2,27)-2,6 $\mu \mathrm{m}$. Tétradas decusadas 45,3-(50,52)-54,6 $\mu \mathrm{m}$; granos $24,7-(26,93)-29,4 \mu \mathrm{m}(\mathrm{P})$ y $35,5-(37,80)-$ $39,3 \mu \mathrm{m}(\mathrm{E})$, poros $4,3-(5,19)-5,8 \mu \mathrm{m}$; exina reticulada, 2-(2,41)-3 $\mu \mathrm{m}$ de espesor (Fig. 6 G-I).
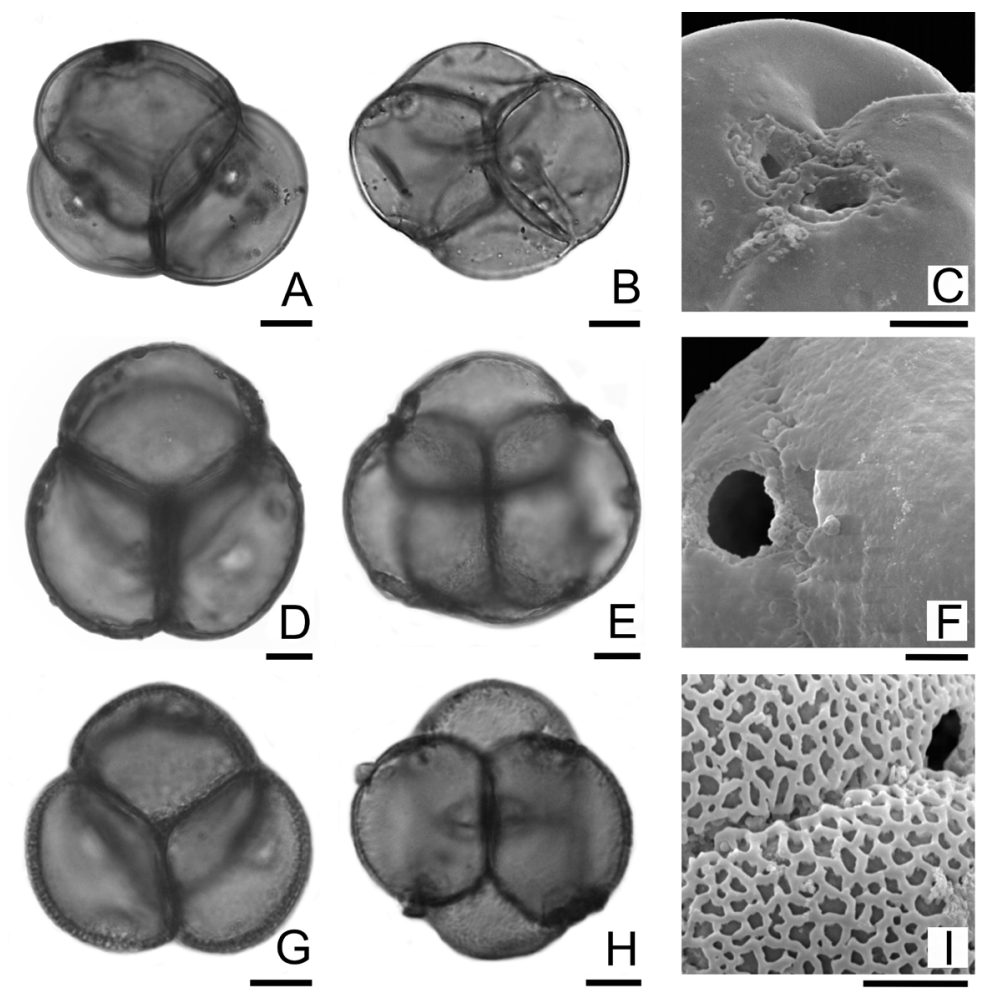

Fig. 6. Tétradas de polen. A-C. Randia calycina. A. Tétrada tetraédrica. B. Tétrada decusada. C. Detalle del poro y de la exina psilada. D-F. R. ferox. D. Tétrada tetraédrica. E. Tétrada decusada. F. Detalle de la exina psilada. G-I. R. micracantha. G. Tétrada tetraédrica. H. Tétrada decusada. I. Detalle de la exina reticulada. Escalas: A-B, D-E, G-H = $10 \mu \mathrm{m} ; \mathbf{C}, \mathbf{F}, \mathbf{I}=5 \mu \mathrm{m}$. 
Bol. Soc. Argent. Bot. 50 (4) 2015
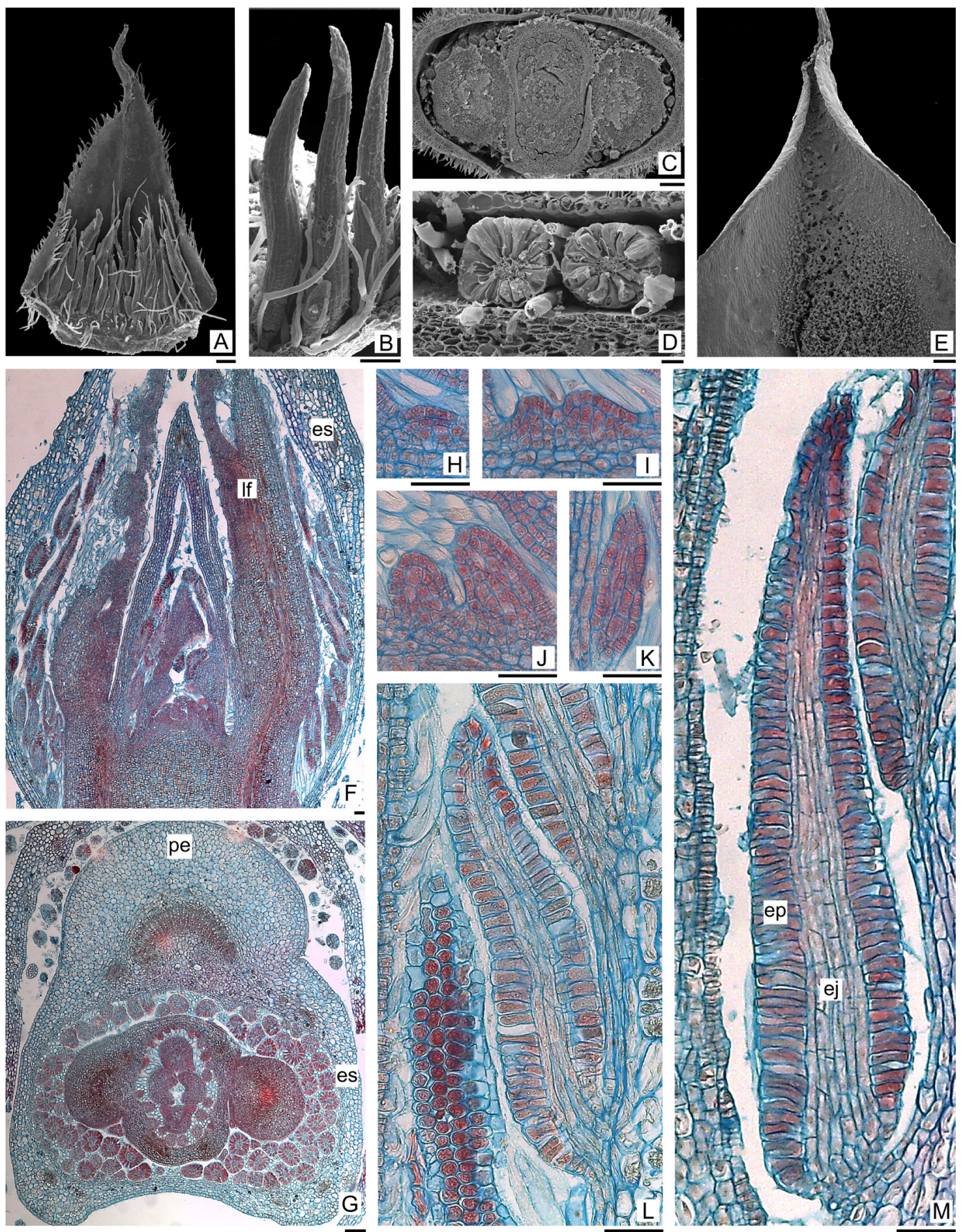

Fig. 7. Microfotografías de las estípulas y sus coléteres. A, C. Randia calycina. B. R. ferox. D-M. $R$. micracantha. A. Cara interna de la estípula con coléteres y tricomas no glandulares. B. Detalle de los coléteres. C. Ápice vegetativo en corte transversal. D. Detalle de los coléteres en corte transversal. E. Detalle de la cara interna de la estípula con depósito de secreción. F. Ápice vegetativo en corte longitudinal. G. Ápice vegetativo en corte transversal. H-M. Ontogenia del coléter. M. Coléter completamente desarrollado. Referencias: ej: eje parenquimático, ep: epidermis, es: estípula, If: lámina foliar, pe: pecíolo. Escalas: A, C $=200 \mu \mathrm{m} ; \mathbf{B}, \mathbf{E}=100 \mu \mathrm{m} ; \mathbf{D}=20 \mu \mathrm{m} ; \mathbf{F}-\mathbf{M}=50 \mu \mathrm{m}$. 


\section{D. Judkevich et al. - Randia (Rubiaceae) en Argentina}

\section{Estudios morfo-anatómicos \\ Coléteres}

Morfoanatomía: los coléteres se encuentran en la base de la cara interna de las estípulas, acompañados por tricomas simples no glandulares (Fig. 7 A, C, F, $\mathrm{G})$. En $R$. ferox miden en promedio $800 \times 142 \mu \mathrm{m}$, en $R$. micracantha $600 \times 99,75 \mu \mathrm{m}$ y en $R$. calycina $534,33 \times 78,12 \mu \mathrm{m}$. Morfológicamente tienen un cuerpo cónico y alargado, con constricción basal, correspondiendo al tipo estándar (Fig. 7 B, $\mathrm{D}, \mathrm{M})$. Anatómicamente presentan un eje central formado por células parenquimáticas rectangulares y alargadas en sentido longitudinal, sin espacios intercelulares. El eje está rodeado por una epidermis uniestratificada y compacta, que presenta células de paredes celulósicas delgadas, citoplasma denso y núcleo conspicuo (Fig. $7 \mathrm{M}$ ). No tienen vascularización. La secreción es mucilaginosa y se deposita en el interior de la estípula (Fig. 7 E).

Ontogenia: los coléteres se originan de la protodermis y del meristema fundamental subyacente. Las células meristemáticas se distinguen por presentar un núcleo esférico conspicuo. Las células de la protodermis sufren divisiones anticlinales y las del meristema fundamental subyacente sufren divisiones anticlinales y periclinales, formando un pequeño domo (Fig. 7 H-I). Con las sucesivas divisiones celulares éste se elonga, las células derivadas de la protodermis se alargan en sentido perpendicular al eje constituyendo la epidermis y las originadas del meristema fundamental lo hacen en sentido longitudinal originando el eje del coléter (Fig. 7 J-L). Tras numerosas divisiones la emergencia finalmente alcanza la forma cónica que caracteriza al coléter maduro (Fig. 7 M).

\section{Anatomía foliar}

Domacios: de las especies que habitan Argentina sólo se encontraron domacios en $R$. ferox, están ubicados en la cara abaxial, en la intersección entre la vena principal y las venas secundarias (Fig. 8 B). Están formados por un grupo denso de tricomas simples, unicelulares o pluricelulares uniseriados, rectos, que varían en longitud y se entrelazan entre sí. Pertenecen al tipo "mechón de pelos". En la cara adaxial de la lámina se observa una protuberancia o domo a la altura del domacio. El mesófilo en la región del domacio conserva las mismas características que en el resto de la lámina foliar.

\section{Vista superficial}

Indumento: formado por tricomas simples, en general unicelulares (Fig. 8 E, G), ocasionalmente pueden ser pluricelulares, uniseriados (Fig. $8 \mathrm{~F}$, $\mathrm{H}$ ), formados por hasta dos células en R. ferox y cinco células en $R$. micracantha (solo en las hojas del PV). En $R$. calycina los tricomas son rectos y están distribuidos en toda la lámina, siendo más abundantes en la cara inferior (Figs. 2 C, 8 A). En $R$. ferox los tricomas son rectos y están distribuidos a lo largo de las venas (Figs. 3 C, 8 B). En R. micracantha los tricomas de la hoja del PF son cortos y curvos y los de la hoja del PV son largos, rectos o levemente curvos, en ambas hojas se encuentran densamente distribuidos en ambas caras (Fig. 8 C-D).

Epidermis: en las tres especies es uniestratificada, la cutícula es lisa. En $R$. calycina en ambas epidermis las células son poligonales, variables en tamaño y con las paredes anticlinales rectas (Fig. 8 I, M, Q). En $R$. ferox ambas epidermis presentan células poligonales, las paredes son sinuosas (Fig. $8 \mathrm{~J}, \mathrm{~N}, \mathrm{R}$ ). En $R$. micracantha ambas epidermis pertenecientes a la hoja del PF presenta células poligonales, de distintos tamaños, con paredes levemente sinuosas (Fig. $8 \mathrm{~K}, \mathrm{O}, \mathrm{S}$ ); en la hoja del PV las células de ambas epidermis tienen forma irregular y paredes marcadamente onduladas (Fig. $8 \mathrm{~L}, \mathrm{P}$, T).

Estomas: las tres especies presentan estomas paracíticos, con dos células anexas de distinto tamaño y forma irregular (Fig. $8 \mathrm{M}-\mathrm{T}$ ). En $R$. calycina y $R$. micracantha (hoja del PF) también hay estomas gigantes (Fig. $8 \mathrm{M}, \mathrm{O}, \mathrm{Q}, \mathrm{S}$ ), que presentan estrías cuticulares en las células que los rodean, en $R$. micracantha pueden estar rodeados por 4-7 células epidérmicas y en $R$. calycina por 2-4 células. La densidad y tamaño de los estomas de las especies analizadas se muestra en la Tabla 1 .

\section{Vista transversal}

Epidermis: en $R$. calycina en la epidermis superior las células son cuadrangulares a rectangulares y de mayor tamaño que las de la epidermis inferior, que tiene células cuadrangulares, rectangulares y redondeadas. En R. ferox las células son cuadrangulares o rectangulares, las de la epidermis superior de mayor tamaño que las de la 

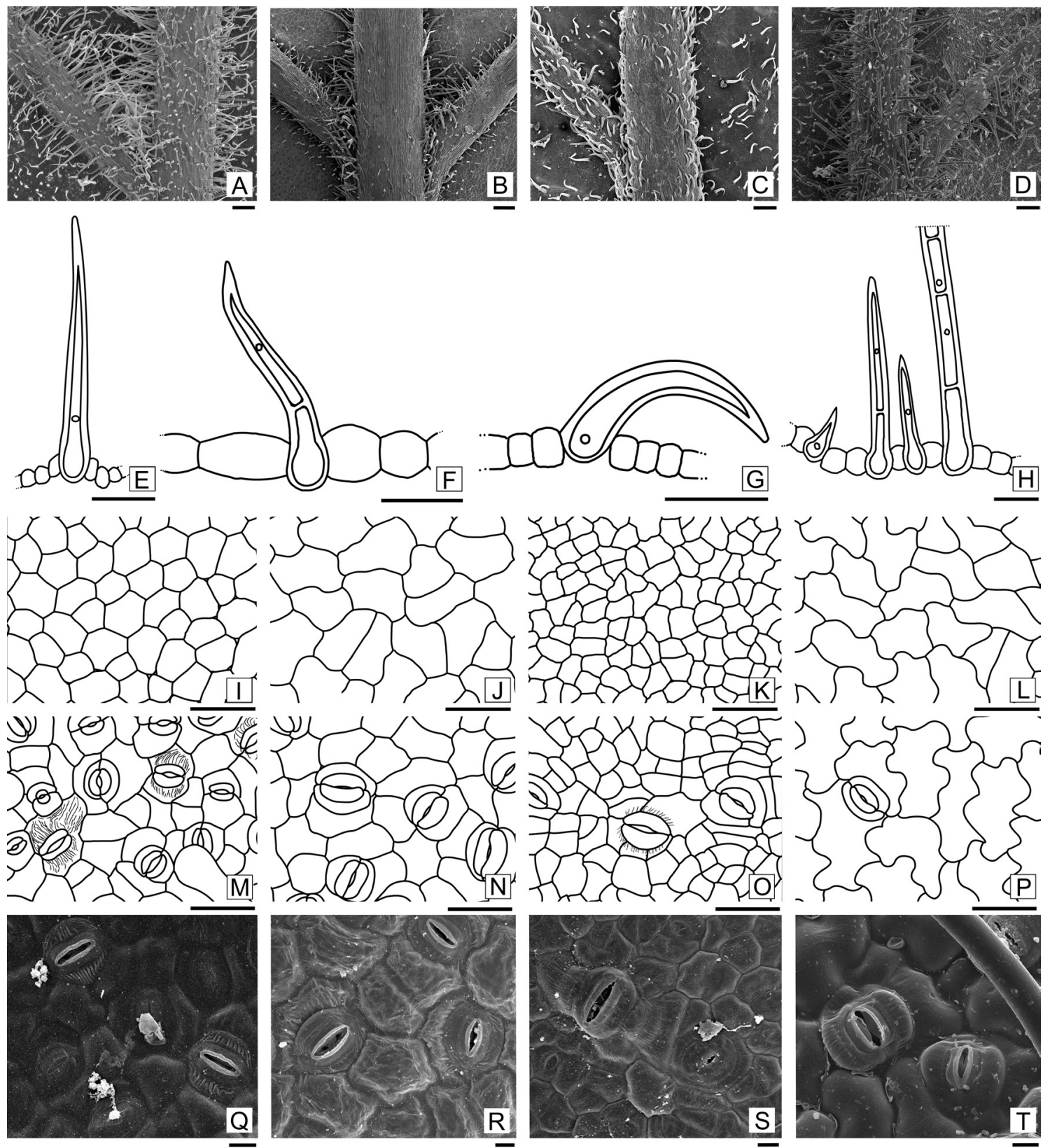

Fig. 8. Anatomía foliar en vista superficial. A, E, I, M, Q. Randia calycina. B, F, J, N, R. R. ferox. C, G, K, O, S. R. micracantha, hojas del PF. D, H, L, P, T. R. micracantha, hojas del PV. A, C-D. Hojas sin domacios, cara abaxial, distribución de pelos. B. Hoja con domacios, cara abaxial, distribución de pelos. E-G. Pelos unicelulares. F, H. Pelos pluricelulares uniseriados. I-L. Epidermis superior. M-T. Epidermis inferior con estomas. Escalas: $\mathbf{A}-\mathbf{D}=200 \mu \mathrm{m} ; \mathbf{E}-\mathbf{P}=50 \mu \mathrm{m} ; \mathbf{Q}-\mathbf{T}=10 \mu \mathrm{m}$.

epidermis inferior. En $R$. micracantha en ambos tipos de hojas las células de la epidermis superior son rectangulares o levemente redondeadas y las de la epidermis inferior son cuadradas o redondeadas.
Estomas: en las tres especies los estomas paracíticos se encuentran al mismo nivel que el resto de las células epidérmicas (Fig. 9 A, C-D). Los estomas gigantes de $R$. calycina y $R$. ferox 
M. D. Judkevich et al. - Randia (Rubiaceae) en Argentina

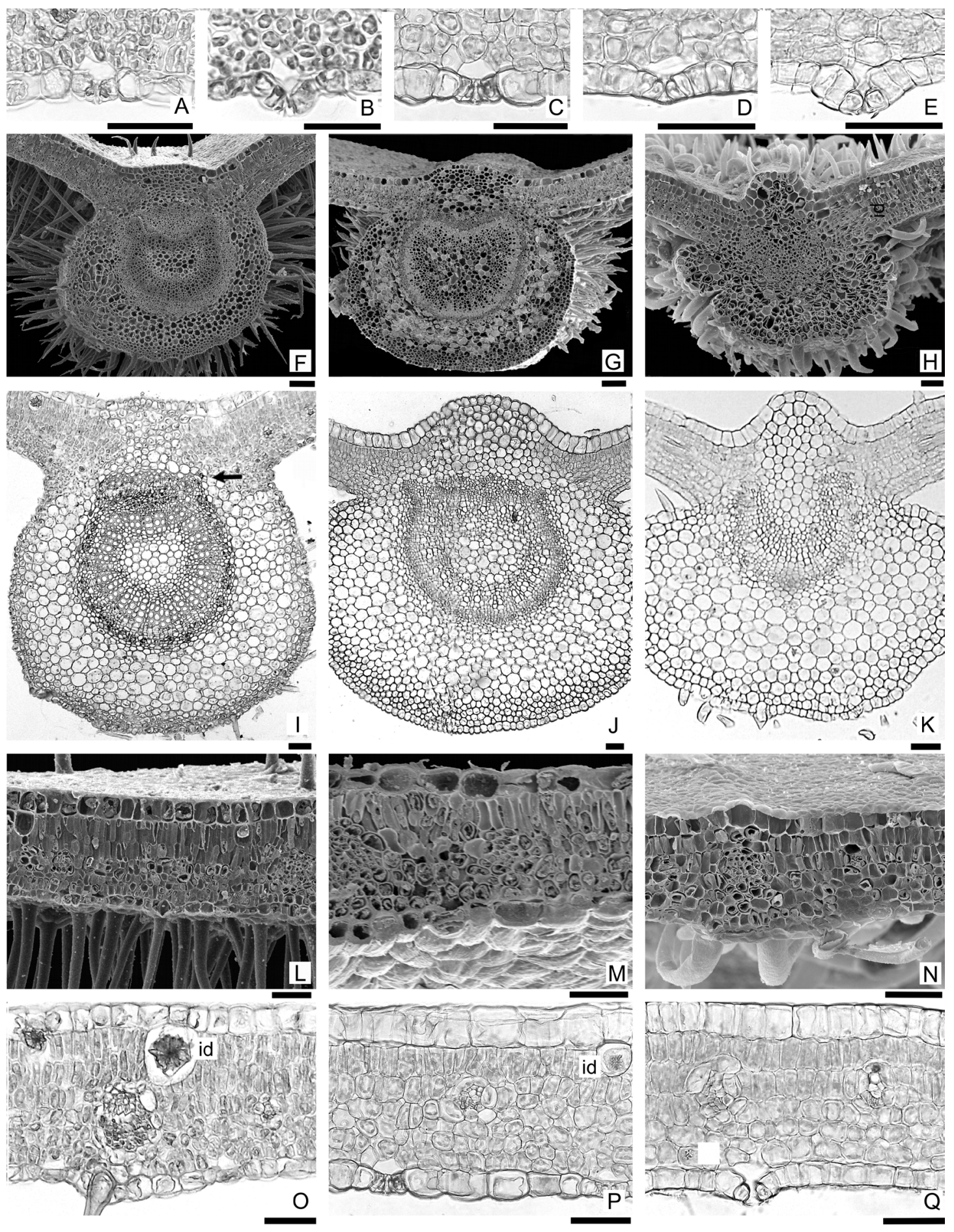

Fig. 9. Anatomía foliar en corte transversal. A, B, F, I, L, O. Randia calycina. C, G, J, M, P. R. ferox. D, E, H, K, N, Q. R. micracantha. A, C, D. Estomas paracíticos. B, E. Estomas gigantes. F-I. Vena media con sifonostela y haz accesorio dorsal (flecha). G, J. Vena media con sifonostela. H, K. Vena media con haz en arco. L-Q. Mesófilo. Referencias: id: idioblastos con drusas. Escalas: $\mathbf{A}-\mathbf{E}, \mathbf{I}-\mathbf{Q}=50 \mu \mathrm{m} ; \mathbf{F}-\mathbf{H}=100 \mu \mathrm{m}$. 
Tabla 1. Densidad, longitud y ancho de los estomas de las especies analizadas de Randia.

\begin{tabular}{|lcccc|}
\hline \multicolumn{1}{|c}{ Especies } & \multicolumn{2}{c|}{ Estoma paracítico } & \multicolumn{2}{c|}{ Estoma gigante } \\
\cline { 2 - 5 } & Densidad & Longitud $\mathrm{x}$ ancho $(\mu \mathrm{m})$ & Densidad & Longitud $\mathrm{x}$ ancho $(\mu \mathrm{m})$ \\
\hline R. calycina & $335 / \mathrm{mm}^{2}$ & $17,39-25,09 \times 13,41-18,61$ & $49 / \mathrm{mm}^{2}$ & $22,64-33,45 \times 15,36-18-72$ \\
R. ferox & $147 / \mathrm{mm}^{2}$ & $28,63-39,06 \times 16,52-23,24$ & - & - \\
R. micracantha (hoja PF) & $69 / \mathrm{mm}^{2}$ & $26,73-34,43 \times 19,82-27,93$ & $11 / \mathrm{mm}^{2}$ & $36,27-47,68 \times 24,47-29,85$ \\
R. micracantha (hoja PV) & $67 / \mathrm{mm}^{2}$ & $26,41-31,83 \times 18,14-21,67$ & - & - \\
\hline
\end{tabular}

están más elevados que las células que los rodean (Fig. 9 B, E).

Vena media: en $R$. calycina está conformada por una sifonostela ectofloica con médula parenquimática y un haz vascular dorsal grande con xilema invertido (Fig. 9 F, I). En $R$. ferox presenta solo una sifonostela ectofloica con médula parenquimática. Hay idioblastos con drusas en el parénquima que rodea al haz vascular (Fig. 9 G, J). Randia micracantha presenta un haz vascular en forma de arco, idioblastos con drusas en el parénquima y células parenquimáticas que contienen numerosos granos de almidón (Fig. 9 $\mathrm{H}, \mathrm{K})$. Hay colénquima en ambas caras de la vena media en las tres especies.

Mesófilo: las tres especies tienen mesófilo dorsiventral y haces vasculares colaterales; cuando existen, las extensiones de la vaina fascicular están constituidas por parénquima. En $R$. calycina el parénquima en empalizada consta de 3-4 capas de células. El parénquima lagunoso presenta 4-6 capas de células (Fig. 9 L, O). Hay idioblastos con drusas, los del mesófilo en empalizada son más grandes y pueden ocupar la misma altura que éste. Los haces están libres o semitrabados a la cara abaxial. En $R$. ferox el parénquima en empalizada es 1-2 estratificado (Fig. 9 M, P). El parénquima lagunoso presenta 3-6 capas de células. Los haces son libres o semitrabados a la cara adaxial. En $R$. micracantha ambos tipos de hojas presentan el mismo espesor y anatomía, el parénquima en empalizada es 1-2 estratificado (Fig. $9 \mathrm{~N}$, Q). El parénquima lagunoso tiene 4-5 capas de células. Los haces son trabados, semitrabados a la epidermis superior y libres.

\section{Discusión}

\section{Taxonomía}

En Argentina se reconocían dos especies de Randia: $R$. ferox del NE y $R$. micracantha del NO, en este trabajo se cita una tercera especie para el país: $R$. calycina, distribuida en el $\mathrm{E}$ de Formosa y NE de Chaco. Esta nueva cita representa el límite sur de la distribución para dicha especie. Se observó que en los herbarios consultados, Randia armata es un nombre ampliamente usado en la identificación de especímenes colectados en el área de estudio. El análisis comparativo entre material de $R$. armata de Centroamérica (comprende la localidad tipo) con material de Argentina, demostró que esta especie no habita el área de estudio coincidiendo con lo propuesto por Delprete et al. (2005).

Por otro lado, se confirmó que el polen de las tres especies se libera en tétradas permanentes como fuera previamente mencionado por Persson (1993). Además, se cita por primera en especies argentinas de Randia, la coocurrencia de dos formas de tétradas en una misma especie: tetraédrica y decusada. Si bien se analizaron pocas especies, en el área de estudio se reconocen dos grupos bien diferenciados por el tipo de exina: una psilada con ausencia de columelas ( $R$. calycina y $R$. ferox), y otra semitectada columelada ( $R$. micracantha).

Además del polen, ambos grupos se diferencian principalmente por la disposición de las espinas (rama con un único nudo de espinas $v s$. ramas con dos o más nudos de espinas) y el ambiente donde crecen (áreas boscosas o abiertas estacionalmente anegables $v s$. bosques estacionalmente secos). Estos aportes apoyan los datos obtenidos por Gustafsson \& Persson (2002), quienes demostraron que en la 
concepción actual Randia es un taxón parafilético con tres linajes diferentes, cuyas especies aparecen entremezcladas con otros géneros de Gardenieae morfológicamente bien delimitados (ej. Tocoyena Aubl., Sphinctanthus Benth. y Rosenbergiodendron Fagerl.). El primer linaje corresponde a Randia s.s. (incluye a la especie tipo, Randia aculeata L.), presenta especies centroamericanas y caribeñas con el cáliz cupuliforme. El segundo linaje es de Sudamérica, habita principalmente en bosques de terrenos bajos temporalmente inundados y se diferencia por tener flores grandes, blancas y muy fragantes. El tercer linaje consta de especies exclusivas de los Andes sudamericanos cuyas flores son pequeñas, con escaso aroma y de color verde-amarillento. Dos de los tres linajes de Randia habitan el área de estudio y están representados aquí por el grupo $R$. calycina y $R$. ferox (linaje sudamericano) y por $R$. micracantha (linaje andino).

\section{Anatomía}

Coléteres: el tipo y ubicación de coléteres en las especies aquí estudiadas coincide con lo conocido en la tribu Gardenieae (Robbrecht, 1988). Además, la ausencia de coléteres en piezas florales coincide con lo expuesto por Gustafsson (1998), quien utilizó dicho carácter para diferenciarlo del género cercano Rosenbergiodendron Fagerl.

Domacios: la presencia de esta estructura en $R$. ferox permite diferenciarla de las otras especies que habitan en el área de estudio, sin embargo en otros grupos de plantas no es un carácter constante y de valor taxonómico (Gonzalez, 2011).

Indumento: las tres especies tienen diferencias en forma y distribución de tricomas. Si bien todas tienen pelos simples unicelulares, R. ferox y $R$. micracantha (hojas del PV) también tienen pelos pluricelulares uniseriados.

Epidermis: en las tres especies se encontraron diferencias en la forma de las paredes anticlinales de las células epidérmicas, paredes rectas en $R$. calycina, sinuosas en $R$. ferox y $R$. micracantha (hoja PF) y onduladas en $R$. micracantha (hojas $\mathrm{PV})$.

Estomas: todas las especies presentaron estomas paracíticos. En $R$. calycina y $R$. micracantha (hojas del PF), existe un segundo tipo de estomas conocidos como estomas "gigantes", término acuñado por Sitholey \& Pandey (1970). Se los identificó teniendo en cuenta la descripción realizada por Carr
\& Carr (1990, en Katja \& Rank, 2011) para otras familias de Angiospermas: estomas de gran tamaño, distribución solitaria y presencia de estrías en las células epidérmicas que lo rodean, contrariamente a lo usual en Rubiaceae son anomocíticos. Estos estomas ya han sido descriptos en otras especies de la tribu Gardenieae (Patil \& Patil, 2011) y de la familia Rubiaceae (Carmo de Oliveira et al., 2010), pero no se ha establecido su relevancia taxonómica.

Vena media: la estructura de los tejidos vasculares difiere en las tres especies: $R$. calycina presenta una sifonostela con un haz accesorio dorsal, en $R$. ferox hay solo una sifonostela y en $R$. micracantha hay un haz en forma de arco. La distribución de los tejidos vasculares de la vena media podría ser un carácter útil en la diagnosis a nivel de género (MartínezCabrera et al., 2009). En el presente trabajo permite diferenciar a las tres especies analizadas.

Mesófilo: las tres especies presentan mesófilo dorsiventral, idioblastos con drusas y haces vasculares colaterales, como es común en varios géneros de Rubiaceae (Accorsi, 1947; Erbano \& Duarte, 2010; Carmo de Oliveira et al., 2010; Ribeiro et al., 2011).

Se puede concluir que caracteres tales como el tipo de exina de los granos de polen, el tipo y distribución del indumento en las hojas, la forma de las paredes anticlinales de la epidermis foliar y la distribución de los tejidos vasculares en la vena media permiten de manera fehaciente la diferenciación entre las especies argentinas de Randia.

\section{Agradecimientos}

Los autores agradecen a los curadores de los herbarios CORD, CTES, JUA, LIL, MCNS, MO, SI y USZ, por la accesibilidad de los materiales; a los revisores por las valiosas sugerencias para mejorar el manuscrito; a L. Simón por la ilustración de algunos detalles y pasado a tinta de $R$. calycina. Se agradece a las Fundaciones FAB y ECOS y a Walter Medina y Víctor Dávalos por asistirnos en las tareas de campo en las áreas protegidas: Reserva Paraje Tres Cerros y Estación Biológica Guaycolec. Este trabajo es parte de los resultados del doctorado de la primera autora y fue realizado con un subsidio de la Universidad Nacional del Nordeste (PICTO 199/2011). 


\section{Biblografía}

ACCORSI, W. R. A. 1947. Ocorrência das células anexas dos estômatos na família Rubiaceae. An. Esc. Super. Agric. Luiz de Queiroz 4: 412-436.

BACIGALUPO, N. M. 1993. Rubiaceae. En: Cabrera, A. L (ed.), Flora de la Provincia de Jujuy. Colecc. Ci. Inst. Nac. Tecnol. Agropecu. 13(9): 375-437.

BACIGALUPO, N. M., E. L. CABRAL \& C.M. TAYLOR. 2008. Rubiaceae. En: Zuloaga, F. O, O. Morrone \& M. J. Belgrano (eds.), Catálogo de Plantas Vasculares de la República Argentina II. Monogr. Syst. Bot. Missouri Bot. Gard. 107(3): 2871-2920.

BARROS, M. A. A. 1961. Domácias nas Angiospermas: variações na forma e na localização. An. Esc. Super. Agric. Luiz de Queiroz 18: 131-146.

BROUWER, Y. M. \& H. T. CLIFFORD. 1990. An annotated list of domatia bearing species. Notes. Jodrell. Lab. 12: 1-33.

CARMO DE OLIVEIRA, A. R., D. M. SAITER GOMES, A. CARVALHO DE AZEVEDO, M. LIMA MAGALHÃES \& M. GOMES. 2010. Anatomia e micromorfologia foliar de seis espécies de Posoqueria Aublet (Rubiaceae). Rodriguésia 61: 505-518.

CARR, D. J. \& S. G. M. CARR. 1990. Transverse and longitudinal gradients in stomatal size in dicotyledons. Cytobios 61: 41-61.

DELPRETE, P. G. 2010. Rubiaceae. En: Rizzo, J. (ed.), Flora dos Estados Goiás e Tocantins 40 (1-3): 9931006. Goiania, Brasil.

DELPRETE, P. G., L. B SMITH \& R. B KLEIN. 2005. Rubiáceas. Gêneros de G-Z: 20. Gardenia até 46. Tocoyena (com observações ecológicas por Klein, R.; Reis, A. \& Iza, O.). En: Reis A. (ed.). Flora Ilustrada Catarinense 2: 345-843. Herbário Barbosa Rodrigues, Itajaí.

ERBANO, M. \& M. DUARTE. 2010. Morfoanatomia de folha e caule de Genipa americana L., Rubiaceae. Rev. Bras. Farmacogn. 20: 825-832.

ERDTMAN, C. 1966. Pollen morphology and plant taxonomy-Angiosperms (An introduction to palynology). Hafner Publishing Co., New York \& London.

GONZALEZ, A. M. 2011. Domacios y nectarios extraflorales en Bignoniáceas: componentes vegetales de una interacción mutualística. Bol. Soc. Argent. Bot. 46: 271-288.

GONZALEZ, A. M. \& C. L. CRISTÓBAL. 1997. Anatomía y ontogenia de semillas de Helicteres lhotzkyana (Sterculiaceae). Bonplandia 9: 287-294.

GUSTAFSSON, C. 1998. The Neotropical Rosenbergiodendron (Rubiaceae, Gardenieae). Brittonia 50: 452-466.
GUSTAFSSON, C. 2000. Three new species of South American Randia (Gardenieae, Rubiaceae). Novon 10: 201-208.

GUSTAFSSON, C. \& C. PERSSON. 2002. Phylogenetic relationships among species of the Neotropical genus Randia (Rubiaceae, Gardenieae) inferred from molecular and morphological data. Taxon 51: 661-674.

JOHANSEN, D. A. 1940. Plant microtechnique. McGraw-Hill Company Inc, San Francisco.

KATJA, M. B. \& B. RANK. 2011. Stomata dimorphism in dicotyledonous plants of temperate climate. Feddes Repert. 121: 167-183.

LERSTEN, N. R. 1975. Colleter types in Rubiaceae, especially in relation to the bacterial leaf nodule symbiosis. Bot. J. Linn. Soc. 71: 311-319.

LORENCE, D. H. 1986. Glossostipula (Rubiaceae), a new genus from Mexico and Guatemala. Candollea 41: 453-461.

LUQUE, R., H. C. SOUSA \& J. E. KRAUS. 1996. Métodos de coloração de Roeser (1972) modificado e Kropp (1972) visando a substituição do azul de astra por azul de alcião $8 \mathrm{GS}$ ou $8 \mathrm{GX}$. Acta Bot. Bras. 10: 199-212.

MARTINEZ-CABRERA, D., T. TERRAZAS \& H. OCHOTERENA. 2009. Foliar and petiole anatomy of tribe Hameliaeae and other Rubiaceae. Ann. Missouri Bot. Gard. 96: 133-145.

MCNEILL, J., F. R. BARRIE, W. R. BUCK, V. DEMOULIN, W. GREUTER, D. L. HAWKSWORTH, P. S. HERENDEEN, S. KNAPP, K. MARHOLD, J. PRADO, W. F. PRUD'HOMME VAN REINE, G. F. SMITH, J. H. WIERSEMA \& N. J. TURLAND, (eds.). 2012. International Code of Nomenclature for algae, fungi and plants (Melbourne Code). International Association for Plant Taxonomy. http://www.iapt-taxon.org/nomen/ main.php (acceso en 21-VIII-2015)

METCALFE, C. R. \& L. CHALK. 1979. Anatomy of the Dicotyledons. Vol.1. $2^{\mathrm{a}}$ ed. Clarendon Press, Oxford.

MORRONE, J. J. 2014. Biogeographical regionalisation of the Neotropical region. Zootaxa 3782: 1-110.

PATIL, C. R. \& D. A. PATIL. 2011. Investigations on foliar epidermis in some Rubiaceae. J. Phytol. 3: 35-40.

PERSSON, C. 1993. Pollen morphology of the Gardenieae-Gardeniinae (Rubiaceae). Nord. J. Bot. 13: 561-582.

POHL, R. W. 1967. Controlled maceration of grass leaves in 40-80 percent nitric acid for preparation of epidermis for slides. Stain Technol. 42:195-7.

PUNT, W., P. P. HOEN, S. BLACKMORE \& A. Le THOMAS. 2007. Glossary of pollen spore terminology. Rev. Palaeobot. Palynol. 143: 1-81.

RIBEIRO, A. C., T. M. DA SILVA MORAES \& M. DA 


\section{D. Judkevich et al. - Randia (Rubiaceae) en Argentina}

CUNHA. 2011. Micromorfologia e Anatomia Foliar de Especies de Rubiaceae do Parque Nacional de Itatiaia- RJ. Floresta e Ambiente 18: 275-288.

ROBBRECHT, E. 1988. Tropical woody Rubiaceae. Opera Bot. Belg. 1: 272.

SITHOLEY, R. V. \& Y. N. PANDEY. 1970. Giant stomata. Ann. Bot. 35: 641-2.

THOMAS, V. 1991. Structural, functional and phylogenetic aspects of the colleter. Ann. Bot. 68: 287-305.
THOMAS, V. \& Y. DAVE. 1989. Structure, origin, development and senescence of colleters in Nerium indicum Mill. (N. odorum Soland., Apocynaceae). Korean J. Bot. 32: 163-172.

VAN COTTHEM, W. R. J. 1970. A classification of stomatal types. Bot. J. Linn. Soc. 63: 235-246.

Recibido el 26 de junio de 2015, aceptado el 27 de agosto de 2015. 
